\title{
Experimental and numerical analysis of indoor environmental conditions in two physiotherapy facilities in Northern Italy
}

\author{
Luca Zaniboni ${ }^{1, *}$, Giovanni Pernigotto ${ }^{1}$, Andrea Gasparella $^{1}$ and Ardeshir Mahdavi ${ }^{2}$ \\ ${ }^{1}$ Free University of Bozen-Bolzano, Faculty of Science and Technology, Piazza Università 5, 39100 Bolzano, Italy \\ ${ }^{2} \mathrm{TU}$ Wien, Department of Building Physics and Building Ecology, Karlsplatz 13, 1040 Vienna, Austria
}

\begin{abstract}
The comfort conditions are fundamental for the well-being of the occupants of a building. The design of both building envelope and HVAC and lighting systems has primarily to keep high quality levels of indoor comfort conditions. This is particularly true for healthcare facilities, where a comfortable environment can mean both a faster healing of the patients and a higher productivity rate of the employees. In this research, a comfort survey is carried out in two physiotherapy facilities in Bolzano, Italy. Long- and short-term measurements of air temperature and relative humidity and short-term measurements of mean radiant temperature, air velocity, illuminance, $\mathrm{CO}_{2}$ and $\mathrm{CO}$ concentrations are taken in the environments where the therapies are performed, from summer to autumn of the year 2018. The long-term conditions are monitored using HOBO sensors, with a 10-minute recording timestep, and installed approximately at the height of $1 \mathrm{~m}$, to evaluate the conditions at the same level at which the therapies are performed. A DeltaOhm HD32.1 microclimatic station with several probes is employed in similar positions for short term monitoring periods. During the whole survey, according to their availability, employees and patients are asked to assess thermal, light, acoustic comfort and air quality by means of questionnaires, developed starting from standards and previous works in literature. In details, anonymous questions are asked to collect data about personal conditions (sex, age, weight, height, clothing level, self-evaluation of the health status), comfort evaluations (seven points scale questions), type of detected discomfort issues (multiplechoice questions), date, time and room where the treatment is performed. Thanks to the data measured at the same times of the questionnaires' answers, Fanger's comfort indexes are calculated according to the technical standard EN ISO 7730 and compared with the real votes collected using the questionnaires. The results, together with a previous analysis made in Vienna in 2015, give good suggestions about the diagnosis of the indoor environmental quality and the control of the HVAC systems in this kind of facilities.
\end{abstract}

\section{Introduction}

A considerable amount of energy is consumed every year to keep indoor thermal comfort conditions [1], which, in turn, can strongly affect both people's productivity and performance [2]. In some environments, however, different activities are performed at the same time by occupants characterized by different personal factors and needs (e.g., metabolic rates and clothing) making a global optimization of thermal comfort difficult [3]. Healthcare facilities are an example of such environments since their occupants can be distinguished into patients and medical staff. Thermal comfort for these two groups can be significantly different since, besides activities and clothing levels, patients can suffer from pathologies and disabilities, which may affect also their thermal perception [3, 4]. Therefore, as observed by Verheyen et al. [5], dedicated studies are necessary for these specific indoor environments. Nevertheless, the number of the studies on healthcare facilities is still very limited. Moreover, the Predicted Mean Vote (PMV) model and comfort criteria of ASHRAE Standard 55 are hardly applicable to healthcare facilities occupants [6]. In fact, Fanger's thermal comfort model $[7,8]$ is based on experiments performed with healthy adult people in a controlled environment under steady state conditions. For this reason, inaccuracies can arise if Fanger's model is applied under different circumstances. Some studies were made on comfort in hospitals [3, 5, 6, 9-13]: however, while in some cases [13] experimental results are more correlated to $P M V$ predictions, in most of the cases [3, 5, 6, 9-12] there are discrepancies. In general, it seems that the topic needs to be deepened with more field studies. In this work, an analysis of the comfort conditions for employees and patients of two physiotherapy centres in Bolzano, Italy, is performed, during a four-month period. Short- and long-term measurements were collected, with the aim of characterizing the environment and calculating the Predicted Mean Vote $P M V$ and Predicted Percentage Dissatisfied $P P D$ indexes. Interviews were conducted by means of questionnaires, in order to investigate the thermal, visual, acoustical comfort and indoor air quality conditions. The thermal comfort results were compared

\footnotetext{
* Corresponding author: Luca.Zaniboni@natec.unibz.it
} 
with the Fanger's model. The outcomes were also compared with another study made by the authors, in which a physiotherapy centre in Vienna was surveyed [14].

\section{Methodology}

\subsection{Case studies}

Two physiotherapy centres in the city of Bolzano, Italy $\left(\mathrm{HDD}_{18}=2178 \mathrm{~K}\right.$ d e $\left.\mathrm{CDD}_{18}=504 \mathrm{~K} \mathrm{~d}\right)$, were considered for the analysis.

\subsubsection{Facility 1}

Facility 1 is located on the ground floor of a 30-year old building in the centre of Bolzano. The space is characterized by a big atrium with the reception and the waiting room, and several rooms around. There are four physiotherapy cabins for static treatments and one gym for dynamic therapies. Four physiotherapists work in these rooms, performing treatments lasting 30 or 45 minutes. The other rooms are medical studios, offices and storage rooms, not considered in this analysis. The facility map, with the different areas and the positions of the sensors, is reported in Figure 1. The centre is open from 8:00 to 17:00. As many buildings of the same vintage in Bolzano, the structure has concrete walls and the windows are double glazed. There are no windows in the cabins, which implies the total absence of daylight in those environments. On the contrary, the gym presents a glazed façade South oriented but shadowed by another building nearby. The facility is heated, ventilated and cooled by a mechanical HVAC plant with a central control and thermostat, and air terminals. During summer 2018, some works were made to improve the air conditioning system.

\subsubsection{Facility 2}

Facility 2 is located on the fourth floor of a 2015 building, in the industrial area of Bolzano. As shown in Figure 2, it is characterized by an atrium with the reception and the waiting room, from where a corridor departs, with three physiotherapy cabins and a sport medical studio opening on it. In the northern side of the building, there is a large gym that is used both for dynamic therapies and specific athletic exercises and is connected with the corridor through a large room. In addition, a sport laboratory, used to perform athletic tests, is located here. Other rooms, not part of this research, comprise offices, bathrooms and storage rooms. Different specialists and therapists work in the facility. The treatments can last $30,45,60$ or 120 minutes, and the centre is open from 8:00 to 20:30. The facility has a well-insulated concrete structure with large windows with triple glazings and roller shades under manual control. The facility is heated, ventilated and cooled by a mechanical HVAC plant with independent thermostats in the different rooms.

\subsection{Long-term measurements}

Long-term measurements of dry bulb temperature and relative humidity, $R H$, were taken inside the analysed structures, using 7 and 9 Onset HOBO U12-013 sensors, respectively for Facility 1 and Facility 2 . These devices have an accuracy of $\pm 0.35{ }^{\circ} \mathrm{C}$ for temperature and $\pm 2.5 \%$ for relative humidity at ambient conditions. After being tested, the sensors were installed in the different rooms in positions considered representative for the occupants' perception (Figures 1 and 2), with the number of sensors per room depending on their spatial dimension and characteristics. The logging interval was set equal to 10 minutes, in order to have at least 3 measurements per treatment. Data logging was started in 21/06/2018 at 16:00 in Facility 1 and in 11/07/2018 at 13:00 in Facility 2 and is currently ongoing. The data analysed in this work consider the period ending on $28 / 11 / 2018$

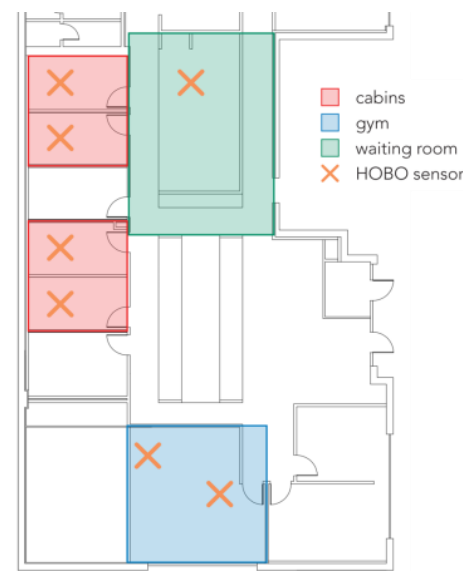

Figure 1. HOBO sensors' positions and areas' characterization in Facility 1

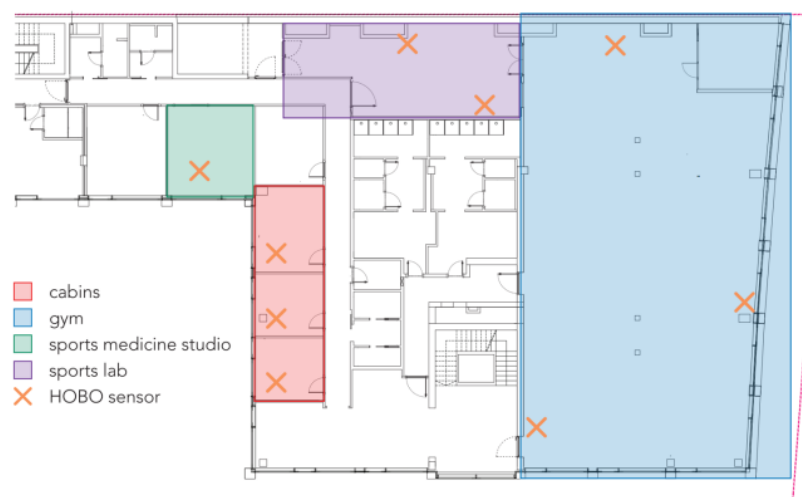

Figure 2. HOBO sensors' positions and areas' characterization in Facility 2

\subsection{Short-term measurements}

Short-term measurements were taken to better characterize the environments and were performed during the whole analysis period. A Delta Ohm HD32.1 Thermal Microclimate data logger with six different probes was used to measure simultaneously dry bulb temperature and relative humidity, mean radiant temperature, air speed and atmospheric pressure (configuration Set Up A) or dry bulb temperature and 
relative humidity, air speed, illuminance, $\mathrm{CO}_{2}$ and $\mathrm{CO}$ concentrations (configuration Set Up C). The monitored quantities were recorded with accuracies of $1 / 3$ DIN for air and mean radiant temperatures, $5 \%$ for relative humidity, $0.02 \mathrm{~m} \mathrm{~s}^{-1}$ for air velocity, $50 \mathrm{ppm}+3 \%$ of the measurement for $\mathrm{CO}_{2}, 3 \mathrm{ppm}+3 \%$ of the measurement for $\mathrm{CO}$ and $1 \mathrm{~lx}$ for illuminance. The data logging was set to take data every $30 \mathrm{~s}$ and several shorttime campaigns were organized during different days. In some of them, also a portable Konika Minolta Illuminance Meter T-10A, with a maximum illuminance measurement of $299900 \mathrm{~lx}$, was used.

The following campaigns were taken in Facility 1 on: - 10/07/2018 afternoon. Weather: cloudy. Set Up A: rooms Physio 1, Physio 2, Physio 4, Physio 5, Gym; Set Up C: Physio 1, Physio 2 and Gym

- 26/07/2018 afternoon. Weather: partly clouded. Set Up A: Gym and Physio 5; Set Up C: Gym and Physio 5 - 06/09/2017 afternoon. Weather: mainly sunny. Set Up A: Physio 2 and Gym; Set Up C: Physio 2 and Gym - 24/10/2018, afternoon. Weather: sunny. Set Up A: Physio 5 and Gym; Set Up C: Physio 5, Physio 1 and Gym.

The campaigns taken in Facility 2 were on:

-11/07/2018 late morning and early afternoon. Weather: sunny with some clouds. Set Up A: rooms Physio 1, Physio 2, Physio 3, Sports Medicine Studio, Sports Medicine Lab and Gym; Set Up C: rooms Physio 1, Physio 2, Physio 3, Sports Medicine Studio, Sports Medicine Lab and Gym

-25/07/2018 afternoon. Weather: partly clouded. Set Up A: rooms Physio 1, Physio 2, Physio 3, Sports Medicine Studio, Sports Medicine Lab and Gym; Set Up C: Physio 1, Physio 2, Physio 3, Sports Medicine Studio, Sports Medicine Lab and Gym

- 12/09/2017 late morning. Weather: sunny. Set Up A: Physio 2, Sports Medicine Studio, Sports Medicine Lab and Gym; Set Up C: Sports Medicine Studio

-25/10/2018, early afternoon. Weather: partly clouded. Set Up A: Physio 1, Sports Medicine Lab and Gym. Portable light meter: Physio 1, Physio 3, Sports Medicine Lab and Gym.

The instrument was located as close as possible to the patients' and therapists' position, and therefore to the long-term sensors' positions.

\subsection{Questionnaires}

Anonymous questionnaires were developed to collect the environmental response of the occupants, both patients and therapists, about the environmental comfort in the different structures. The questionnaires were developed using the ISO 10551 standard [15], ASHRAE Standard 55 [7], EN ISO 7730 standard [8] and previous works found in literature [3-6, 9-13], developing and improving the ones used by the authors in [14]. Questionnaires were submitted to voluntary answerers, before and after each therapy session, therefore their filling was not regular.
Date, time and room where therapies were performed were asked, in order to match the answers with the measurements in data analysis. Answerers were asked to fill the name initials, in order to allow future studies of questionnaire repetitions. Pieces of information about gender, age, weight, height and dressed clothes were collected. Patients were also asked to perform a selfevaluation on their own health status, choosing among "healthy", "slightly weak" and "weak status". On the other hand, physiotherapists were asked to describe the lighting ("on" or "off") and shadings status ("up", "half" or "down"), where present.

The questionnaires were divided into three sections, one to be filled by the employee (section A) and two by the patient, before (B) and after the therapy $(C)$.

All sections included questions about:

- temperature satisfaction: 7-point satisfaction scale $(1 \div 7)$

- and temperature vote: 7-point Likert scale (from "-3 = too cold" to " $+3=$ too hot", " $0=$ neutral").

Sections (A) and (B) comprise also questions about:

- Illuminance, air quality and acoustic satisfaction: 7point satisfaction scale $(1 \div 7)$

- Illuminance, air quality and acoustic main problems: multiple choice answers among the main issues in the three comfort fields (i.e., glare, too low or too high light; bad smell or too dry air; noises or echoes).

\section{Analysis of collected measurements and answers}

\subsection{Long-term measurements}

\subsubsection{Facility 1}

Long-term measurements in Facility 1 show quite variable values in the non-heating period. The temperature in cabins, gym and waiting room floated between $22{ }^{\circ} \mathrm{C}$ and $28{ }^{\circ} \mathrm{C}$, with peaks of $29{ }^{\circ} \mathrm{C}$. The humidity was also floating and was comprised between $30 \%$ and $65 \%$. No particular spatial differences were detected. From October, during the heating period, the temperatures fluctuate around $23{ }^{\circ} \mathrm{C}$ (with peaks of about $26{ }^{\circ} \mathrm{C}$ and $19{ }^{\circ} \mathrm{C}$ ) in cabins and around $21{ }^{\circ} \mathrm{C}$ (with peaks of $23{ }^{\circ} \mathrm{C}$ and $19{ }^{\circ} \mathrm{C}$ ) in Gym. The humidity varied between 30 and $60 \%$. These data suggest some possible discomfort conditions during the cooling period and during the heating period, especially in cabins.

\subsubsection{Facility 2}

The Facility 2 HVAC plant with separate thermostats' regulations kept the temperature and the humidity more constant, with values of about $22{ }^{\circ} \mathrm{C}$ in Cabins 2 and 3, in Lab and Medicine studio and $23{ }^{\circ} \mathrm{C}$ in Cabin 1 and Gym, depending on the type of regulation set by the employees in the rooms. No night-time setback was used. With the exception of some minimum values during the unoccupied periods, the humidity is in the range of $50 \div 60 \%$ in the Gym, and $60 \div 70 \%$ in the 
other rooms. During the heating period, starting at the end of October, the average temperatures went down around $20{ }^{\circ} \mathrm{C}$, with more fluctuations than before. An exception is the Sports' Medicine Studio, where temperatures are lower than $19{ }^{\circ} \mathrm{C}$. Also the relative humidity appears to be more variable in that period, with values around $50 \div 60 \%$ in the first half of November and fluctuating between 30 and $60 \div 70 \%$ later.

\subsection{Short-term measurements}

\subsubsection{Facility 1}

Short-term measurements in Facility 1 show: 1. temperature and $R H$ values in the range found with longterm sensors; 2. air-speed generally under $0.05 \mathrm{~m} / \mathrm{s}$, with some peaks over $1 \mathrm{~m} / \mathrm{s}$ recorded in the Gym; 3 . illuminance of $800 \div 1000 \mathrm{~lx}$ in Cabins with lights on, and around $300 \div 4001 \mathrm{x}$ in Gym during day with lights on; 4. negligible $\mathrm{CO}$ concentration and a concentration of $\mathrm{CO}_{2}$ within $600 \div 700 \mathrm{ppm}$. The illuminance level, the values found in Facility 1 cabins respect the minimum of $3001 x$ suggested by the technical standard EN 12464$1: 2011$ [16] for massage rooms.

\subsubsection{Facility 2}

Short-term measurements in Facility 2 show: 1. temperature and $R H$ values in the range found with long term sensors; 2 . air-speed dependant on the room and the specific position of the probe, with peaks of $2 \mathrm{~m} / \mathrm{s}$ and even of $4 \mathrm{~m} / \mathrm{s}$ in the Gym; 3. high level of illuminance, with peaks of $5000 \mathrm{~lx}$, due to the high level of daylight, and more constant values around $600 \mathrm{~lx}$ in Lab, with no daylight contribution; 4 . negligible $\mathrm{CO}$ concentration and concentration of $\mathrm{CO}_{2}$ not higher than $800 \div 1000$ ppm, with the exception of the Gym, where it is almost always higher than $1200 \mathrm{ppm}$ and up to $2000 \mathrm{ppm}$. For accessibility reasons, no measurements without daylight were made in Facility 2 yet. Anyway, the high values of illuminance found, due to the presence of wide glazed walls, suggest the risk of glare.

\subsection{Questionnaires}

\subsubsection{Facility 1}

61 questionnaires were collected. Among them, 12 were missing the data of date, time, room and therapy length: this made impossible to link these questionnaires with the long-term measurements, and therefore the $P M V$ and $P P D$ value associated. Six questionnaires were filled in Gym, others in cabins. 46 of the therapies performed were static (massages) and 13 dynamic (physical exercises). Both therapy types can last 30 or 45 minutes. The four employees, all born after 1970 and in good health conditions, are two women, who filled 24 questionnaires, and two men, who filled 37 questionnaires. All the employees, wearing the same uniform, had the same clothing level of 0.5 clo. Most of the patients were born in 1960s decade, with 11 patients born before 1950 and 3 after 2000. The $70 \%$ of the patients rated themselves "healthy", while the others considered themselves "slightly weak". No particular correlation was found between the age and the health self-evaluation. The following clothing levels were registered during therapies: $47 \%$ in the range of $0.25 \div$ 0.5 clo, $12 \%$ between 0.5 clo and 0.75 clo and the last $42 \%$ of less than 0.25 clo. Regarding the thermal comfort, the thermal satisfaction and thermal vote seem to be correlated for both employees and patients (Figure 3). Even if both occupant categories present a significant amount of people feeling warm, this is particularly true for employees since a large number of them rated the environment as "slightly warm".
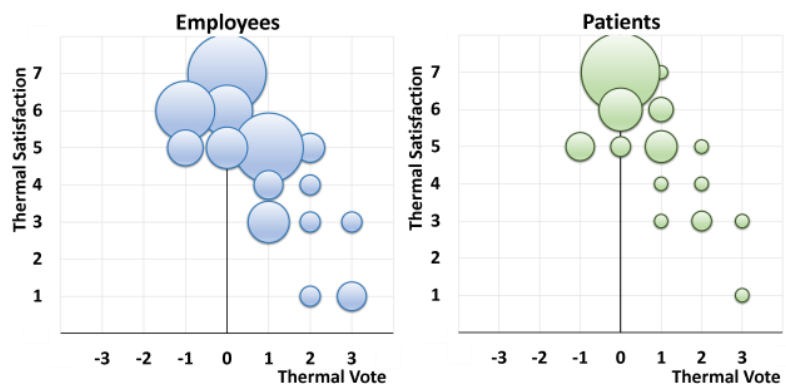

Figure 3. Thermal sensation and thermal vote for employees and patients in Facility 1

No large difference was noticed among the ratings before and after the therapies, even if for 20 patients adaptation mechanisms seem to have occurred, with their ratings changing from "slightly warm" and "slightly cold" to "neutral". No significant differences were found among the different rooms. Light satisfaction presents marked differences between employees and patients' answers. The formers were less satisfied, especially in cabins (Figure 4). This was found out to be due to glare, flash blindness and too high illuminance. Since the illuminance values measured are much higher than the 300 1x suggested by EN 12464-1:2011 [16] for massage rooms for massage rooms, the lighting system appears to be over-sized.

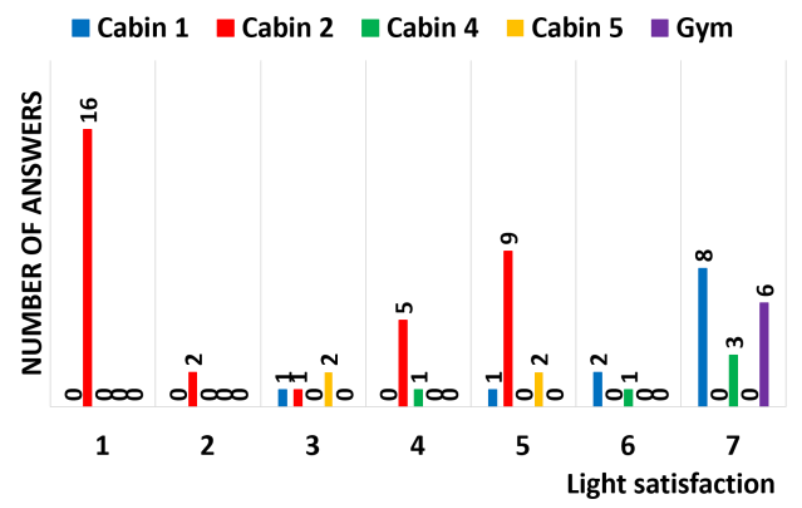

Figure 4. Light satisfaction of employees in the different rooms in Facility 1

Patients were more satisfied with the light conditions (Figure 5), even if $17 \%$ of them stated that light was too high in cabins. Moreover, some therapists reported to 
switch off the main lights and use a portable table light during the treatments; for this reason, both employees and patients rated the light environment better when the room lights are off (Figure 6). $78 \%$ of the employees and $87 \%$ of the patients rated the air quality with more than 5 points out of 7 . The main problems reported by the interviewed, especially by employees, dealt with too dry or too humid air and bad smells. No draught problems were noticed. The occupants were satisfied with the acoustics, even if $69 \%$ of employees' answers reported noises from the HVAC plants. No particular trends were found with the answerers' categories. Among employees, women felt a little warmer, but, since the therapists are four, this difference can be explained with individual perception reasons.

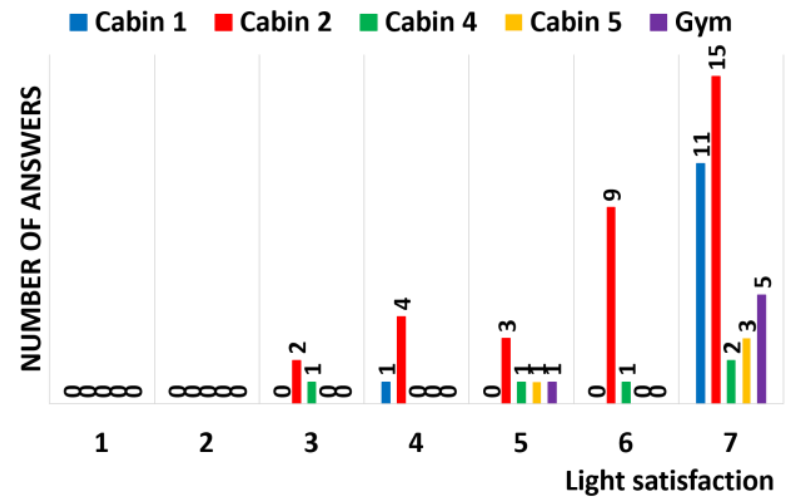

Figure 5. Light satisfaction of patients in the different rooms in Facility 1

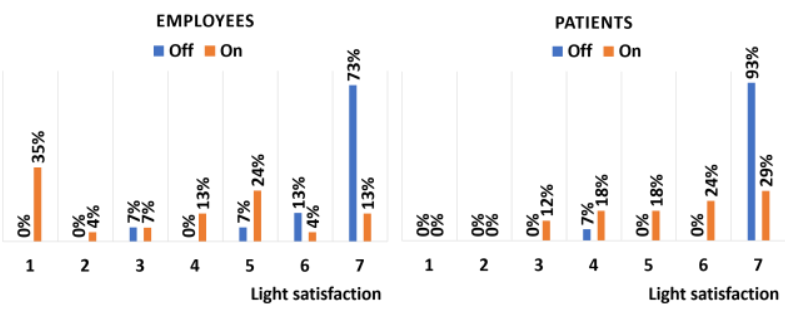

Figure 6. Light satisfaction of employees and patients, depending on the light switching in Facility 1

\subsubsection{Facility 2}

Facility 2 is a new centre, whose activity was still under starting phases during the analysis period. Therefore, it was possible to collect no more than 20 questionnaires with no missing important data such as date, time and room where the treatment was performed. The results were reported anyway, in order to have some preliminary findings. Six questionnaires were filled in cabins, 4 in Sports Lab and 10 in Gym and, so, 14 of them represent dynamic treatments and 6 static therapies. The therapies in cabins lasted 45 minutes, the ones in Lab 45 or 120 minutes, and the ones in Gym lasted 60 or 120 minutes. All the employees were born after 1970 and were in good health. The physiotherapists working in cabins were women, while the others men. $50 \%$ of employees presented a clothing level between 0.5 and 0.75 clo, $40 \%$ between 0.25 and 0.5 clo, and last $10 \%$ between 0.75 and 1 clo. Five patients were born after the
1970, with three after 1990 and two after 2000. Among the others, five were born before of 1950. Eleven patients were women. Thirteen patients rated themselves as "healthy", 5 "slightly weak" and one "weak". No particular correlation was found between the age and the health self-evaluation. Almost all of them had a clothing insulation below $0.5 \mathrm{clo}$, with three elements even below 0.25 clo. Only one patient had a clothing insulation between 0.5 and 0.75 clo.

In agreement with what observed in the other facility, the two scales for thermal sensation seem to be in good agreement (Figure 7). In this case, patients seem to be slightly colder than therapists, even if almost all of them rated the temperature within the "slightly cold" "slightly warm" interval. No significant difference was noticed among the different rooms. Some patients rated the temperature a bit higher, and were therefore more satisfied, after therapy. Both the occupants were satisfied with light and daylight, even if three patients reported too high illuminance (Figure 8). The air quality was found acceptable, but some occupants felt draughts. Someone reported the presence of some reverberation in the gym and some plants' noises in the other rooms.
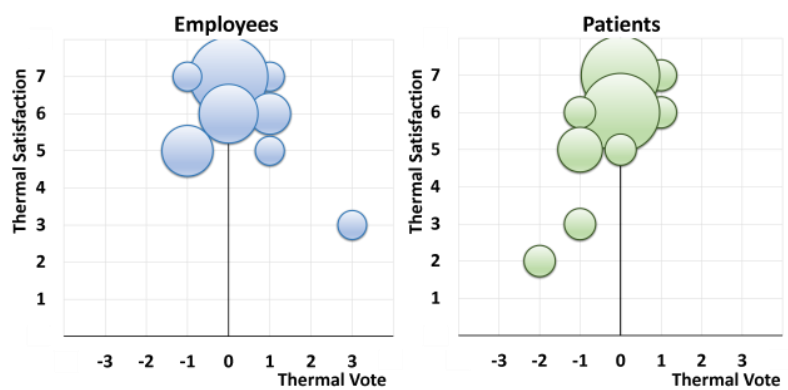

Figure 7. Thermal sensation and thermal vote for employees and patients in Facility 2

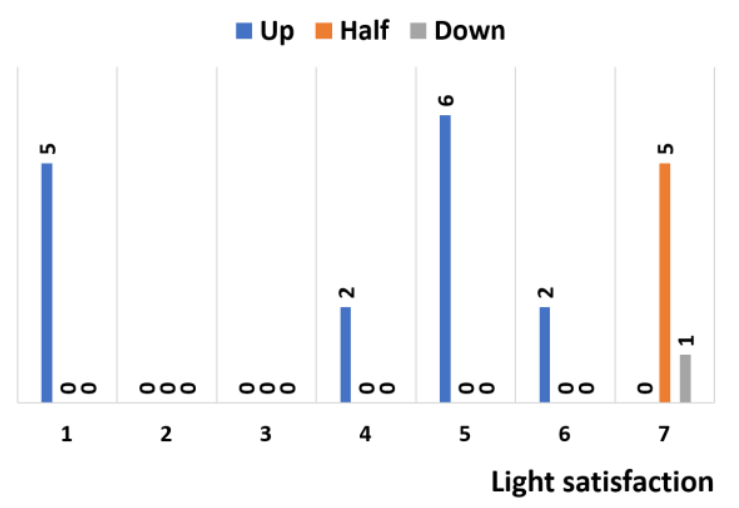

Figure 8. Light satisfaction compared with the shadings position in Facility 2

\section{PMV and PPD calculations and comparisons}

The occupants' answers about thermal comfort were compared with the comfort indexes calculated from the long-term measurements collected at the same time. The procedure is very similar to the one used in [14]. Long term sensors gave the measurements of air temperature 
and relative humidity. On the other hand, mean radiant temperature was available only in short-term monitoring. Linear regressions with respect to air temperature were developed for each room from short term monitoring, to have an estimation of the long term mean radiant temperatures. Since the four cabins of Facility 1 centre are very similar, their data were used together. The data which were clearly outliers, due to some particular conditions present in the rooms in that moments (i.e. open door) were removed. The index of determination $R^{2}$ was calculated for each regression, and only those larger than 0.7 were used to compute mean radiant temperature from long-term values of air temperature. In the other cases, mean radiant temperature was assumed equal to air temperature. This happened only in three rooms of Facility 2: Sports' Lab, Sports' Medical Studio and Gym Short-term measurements average for each room were used for air speed. According to [7, 8], a metabolic rate of 2 met and 1 met were assigned to employees and patients before therapy, while different metabolic rates were imposed to patients after the therapy: 1 met for static treatments, and 3 met for dynamic treatments. The answers to questionnaires permit to assign the clothing level values, according to ASHRAE Standard 55 [7]. Activity and clothing levels, air and mean radiant temperatures, relative humidity and air speed were used to calculate Predicted Mean Votes and Predicted Percentage of Dissatisfied [7, 8, 15]. The box and whiskers $P M V$ and votes distributions and the average results among the different $P P D$ coming from calculated $P M V$ and real votes are reported in Figure 9 for Facility 1. The results show an over estimation of the dissatisfied people, with the occupants feeling more comfortable than predicted. Figure 10 reports the outcomes for Facility 2. In this case, the predicted votes were lower than in Facility 1, meaning a lower $P P D$ for employees and higher for patients. The results show that both employees and patients felt good at the given temperatures. Patients' $P M V$ presents generally spreader values than therapists' ones because of the more various levels of clothing and metabolism. The fact that almost all the employees in Facility 2 rated the temperature "neutral" is probably due to the local thermostatic control: they make possible for therapists to set the temperature according to the occupants' preference. These results are partially in contrast with what was found from a similar analysis made in the Leopoldau physiotherapy centre of Vienna, Austria, in spring 2014 [14], where employees felt warmer while patients rated the temperature to be fine. The comparisons between Leopoldau centre's and Facility 1's votes are reported in Figures 11 and 12. The figures represent the votes against the temperature measured by long term sensors at the moments at which the votes were given or the $P M V$ was calculated. It is possible to notice that employees' $P M V$ has a different distribution in Vienna, because they were not wearing a uniform and the temperatures were less spread. The therapists in Vienna felt hotter and less comfortable, even if the temperature range was more controlled and in the range of $24 \div 26{ }^{\circ} \mathrm{C}$. As already said, patients felt good in both centres. In Bolzano, they might be more tolerant to high temperature because they present a lower level of clothing (Figure 13).

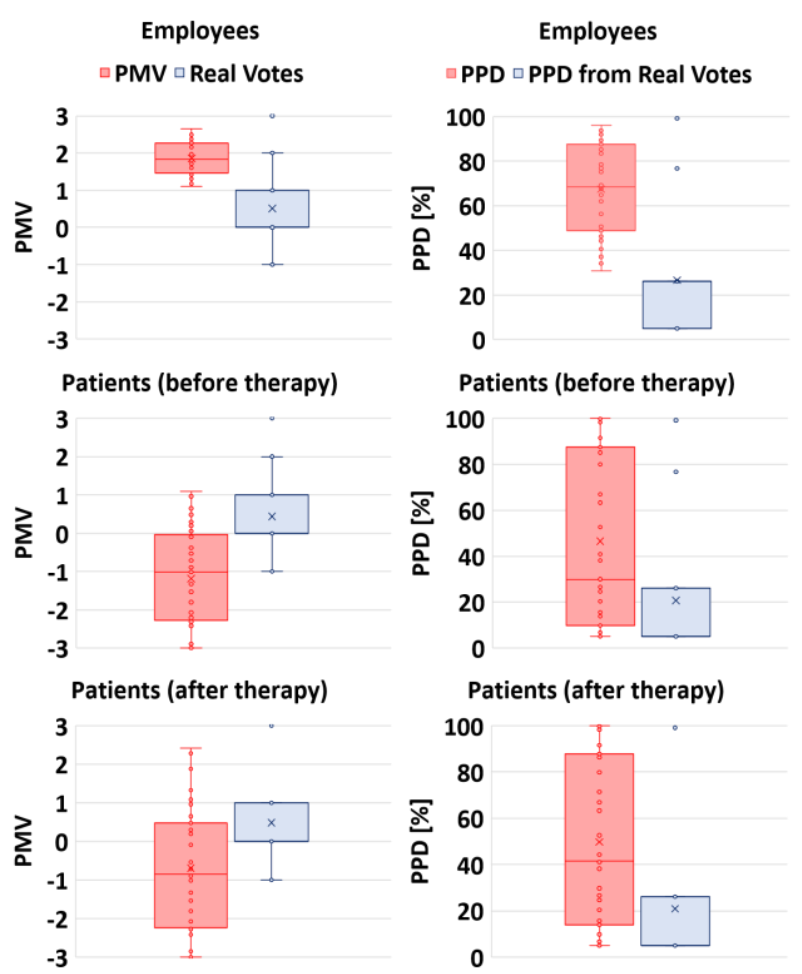

Figure 9. Comparison among Fanger's indexes and real votes and $P P D$ calculated by real votes in Facility 1

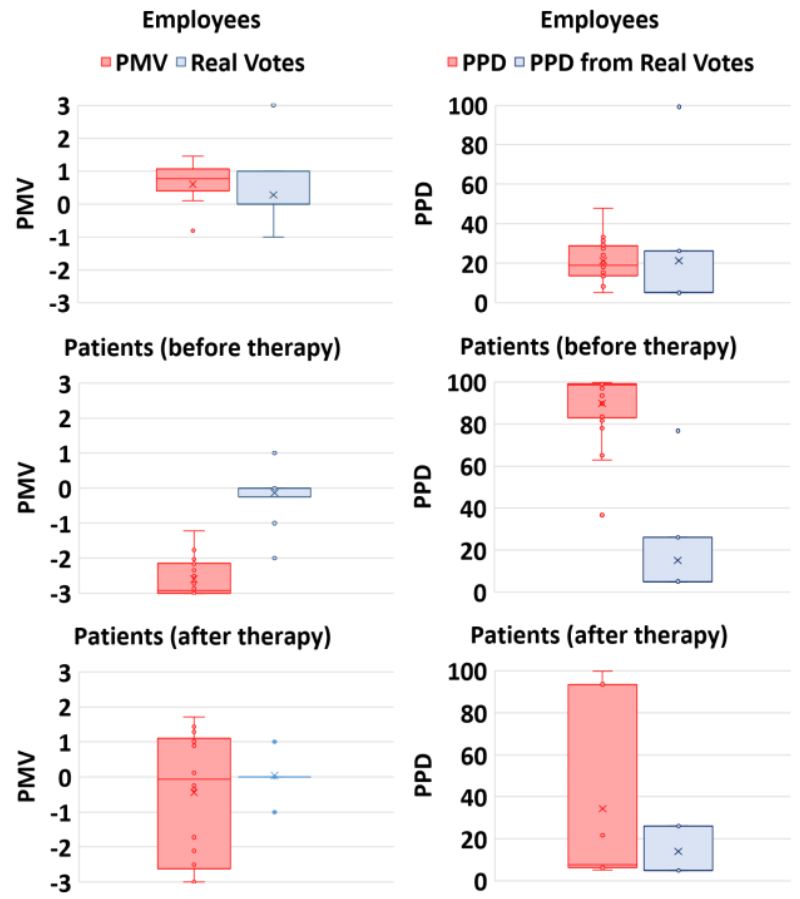

Figure 10. Comparison among Fanger's indexes and real votes and $P P D$ calculated by real votes in Facility 2 


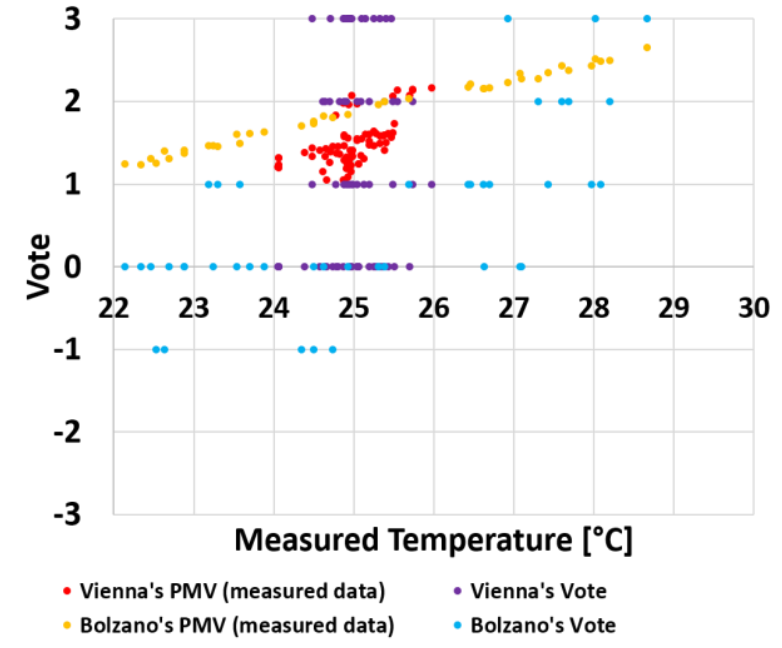

Figure 11 Comparison of employees' Fanger's indexes and real votes in Vienna's centre and Bolzano's Facility 1

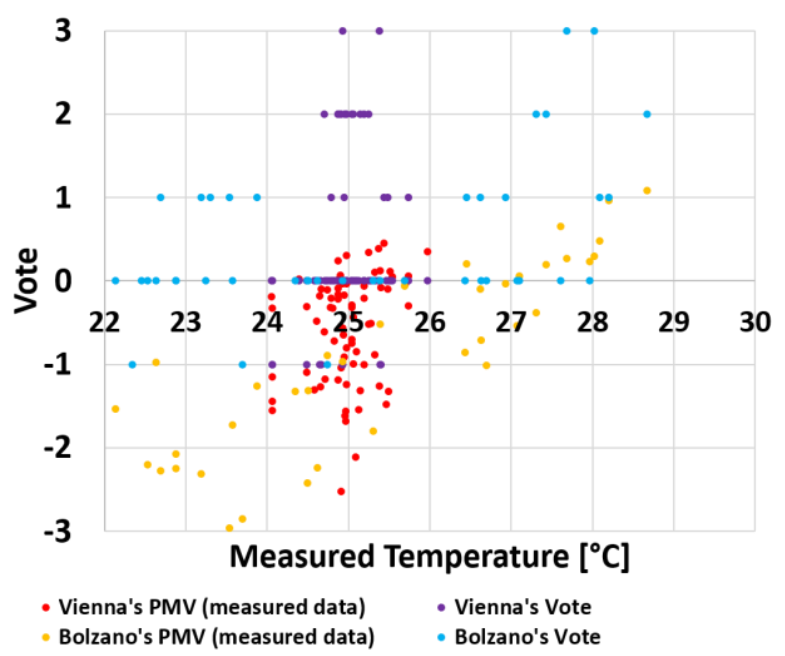

Figure 12 Comparison of patients' Fanger's indexes and real votes in Vienna's centre and Bolzano's Facility 1

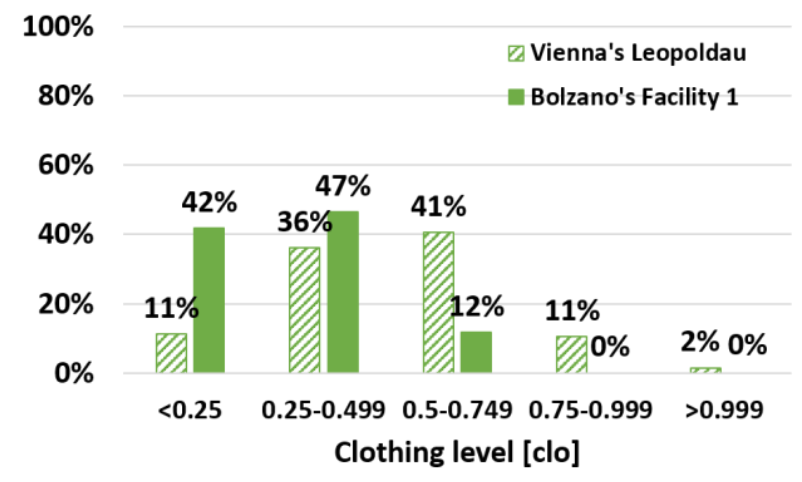

Figure 13 Comparison of the patients' clothing levels in Vienna Leopoldau centre and Bolzano Facility 1

\section{Conclusions}

In this work, the comfort conditions in two physiotherapy centres in Bolzano were assessed by means of both measurements and surveys based on questionnaires, during the period of four months. Thermal, visual, indoor air quality and acoustical comfort were analysed. In particular, thermal comfort was studied using both satisfaction $(1 \div 7)$ and Likert scales (from " $-3=$ too cold" to " $+3=$ too hot", " $0=$ neutral"). The results were compared with the Fanger's indexes Predicted Mean Vote and Predicted Percentage Dissatisfied calculated starting from the measurements collected during the monitoring period.

Analysing the two centres' answers about comfort perception, it is possible to observe that:

1. Employees seem to be more sensitive than patients to indoor air quality, light and acoustics problems, especially in Facility 1. This could be due to their longer permanence in those environments.

2. As regards visual comfort in Facility 1, both employees and patients reported to be annoyed by the high level of artificial lighting. In Facility 2, instead, visual discomfort can be more frequently caused by daylight when shades are completely open.

3. During the summer period in Facility 1, when some critical conditions were measured, humidity and air quality were weighed more than temperature by the occupants in assessing the $I E Q$.

4. In terms of thermal sensation, both employees and patients felt generally good in both centres, even if Facility 1 presented high temperatures, especially in the summer. However, different trends were registered. In the Facility 1 centre, employees felt slightly warmer than patients, and some patients adapted from "slightly warm" and "slightly cold" to "neutral" during the therapy. In the Facility 2 centre, with room controls and more possibilities to change room thermostat settings, therapists felt perfectly comfortable in terms of temperature but some patients, especially before the therapy, felt slightly cold.

5. In general, the occupants felt better than predicted by Fanger's model. No particular correlation was found between age and self-evaluated health status, as well as trends between thermal sensation and answerers' gender or age.

With respect to a previous work performed in a similar centre in Vienna, it is possible to notice that:

1. In Bolzano, employees felt less warm, even when exposed to higher temperatures.

2. Patients felt good in both Vienna and Bolzano centres, even if in the second location higher temperatures were registered. This could be due to the generally lower clothing level.

As it can be observed, from the data collected through surveys and monitoring activities, it is already possible to draw considerations about differences in employees' and patients' comfort perception, which can be exploited to improve the $I E Q$. However, they cover just a period of the year. For this reason, activities performed in this research will be continued to include more seasons and to allow for findings more robust for generalization. 
This study has been funded by the project "Klimahouse and Energy Production" in the framework of the programmaticfinancial agreement with the Autonomous Province of BozenBolzano of Research Capacity Building. The authors kindly thank the two physiotherapy facilities' staff for actively collaborating to develop this research.

\section{References}

1. H. Djamila, Indoor thermal comfort predictions: Selected issues and trends, Renew. Sust. Energ. Rew. 74, 569-580 (2007)

2. K.C. Parsons, Human Thermal Environments. The effect of Hot, Moderate and Cold Environments on Human Health, Comfort and Performance (Taylor and Francis, London, 2003)

3. S. Del Ferraro, S. Iavicoli, S. Russo, V. Molinaro, $A$ field study on thermal comfort in an Italian hospital considering differences in gender and age, Appl. Ergon. 50, 177-184 (2015)

4. J. Skoog, N. Fransson, L. Jagemar, Thermal environment in Swedish hospitals: summer and winter measurements, Energ. Buildings 37, 872-877 (2005)

5. J. Verheyen, N. Theys, L. Allonsius, F. Descamps, Thermal comfort of patients: Objective and subjective measurements in patient rooms of a Belgian healthcare facility, Build. Environ. 46, 1195-1204 (2010)

6. S. Sattayakorn, M. Ichinose, R. Sasaki, Clarifying thermal comfort of healthcare occupants in tropical region: A case of indoor environment in Thai hospitals, Energ. Buildings 149, 45-57 (2017)

7. American Society of Heating, Refrigerating, and Air-conditioning Engineers, ASHRAE Standard 55: Thermal environmental conditions for human occupancy (ASHRAE, Atlanta, 2013)

8. European Committee for Standardisation, Ergonomics of the thermal environment - Analytical determination and interpretation of thermal comfort using calculation of the PMV and PPD indices and local thermal comfort criteria (EN ISO 7730, Brussels, 2005)

9. R.L. Hwang, T.P. Lin, M.J. Cheng, J.H. Chien, Patient thermal comfort requirement for hospital environments in Taiwan, Build. Environ. 42, 29802987 (2007)

10. S. Azizpour, S. Moghimi, E. Salleh, S. Mat, C.H. Lim, K. Sopian, Thermal comfort assessment of large-scale hospitals in tropical climates: A case study of University Kebangsaan Malaysia Medical Centre (UKMMC), Energ. Buildings 64, 317-322 (2013)

11. R. Van Gaever, V.A. Jacobs, M. Diltoer, L. Peeters, S. Valanduit, Thermal comfort of the surgical staff in the operating room, Build. Environ. 81, 37-41 (2014)

12. M.T.H. Derks, A.K. Mishra, M.G.L.C. Loomans, H.S.M. Kort, Understanding thermal comfort perception of nurses in a hospital ward work environment, Build. Environ. 140, 119-127 (2018)
13. A. Pourshaghaghy, M. Omidvari, Examination of thermal comfort in a hospital using PMV-PPD model, Appl. Ergon. 43, 1089-1095 (2012)

14. L. Zaniboni, K. Kiesel, M. Schuß, G. Pernigotto, A. Gasparella, A. Mahdavi, Indoor comfort evaluation of a health care facility: a case study, Clima 2016, (2016)

15. International Organization for Standardization, Ergonomics of the Thermal Environment Assessment of the Influence of the Thermal Environment Using Subjective Judgement Scales, (ISO 10551, Geneva, 1995)

16. European Committee for Standardisation, Light and lighting - Lighting of work places - Part 1: Indoor work places (EN 12464-1. Brussels, 2011) 